Meta

Journal des traducteurs

Translators' Journal

\title{
Consultation
}

\section{Comité de linguistique, Radio-Canada}

Volume 12, numéro 3, septembre 1967

URI : https://id.erudit.org/iderudit/002194ar

DOI : https://doi.org/10.7202/002194ar

Aller au sommaire du numéro

Éditeur(s)

Les Presses de l'Université de Montréal

ISSN

0026-0452 (imprimé)

1492-1421 (numérique)

Découvrir la revue

Citer ce document

Comité de linguistique, Radio-Canada (1967). Consultation. Meta, 12(3), 91-92.

https://doi.org/10.7202/002194ar

Ce document est protégé par la loi sur le droit d'auteur. L’utilisation des services d’Érudit (y compris la reproduction) est assujettie à sa politique d'utilisation que vous pouvez consulter en ligne.

https://apropos.erudit.org/fr/usagers/politique-dutilisation/
Cet article est diffusé et préservé par Érudit.

Érudit est un consortium interuniversitaire sans but lucratif composé de l’Université de Montréal, l’Université Laval et l’Université du Québec à Montréal. Il a pour mission la promotion et la valorisation de la recherche. https://www.erudit.org/fr/ 


\section{CONSULTATION}

\section{Claque OU CAOUTChOUC}

Pour désigner une sorte de double chaussure en caoutchouc qu'on met pardessus le soulier pour le protéger contre la pluie, la neige ou l'humidité en général, il y a deux mots en concurrence au Canada: «claque » et «caoutchouc ».

Claque semble une espèce d'archaïsme en ce sens. Le dictionnaire Robert ne mentionne pas ce sens et donne seulement l'expression «prendre ses cliques et ses claques $\gg$.

Le Larousse du $\mathrm{xx}^{e}$ siècle donne la définition suivante: "sorte de socque plat, que les dames mettaient [sic] par-dessus leur soulier, contre la boue et l'humidité ». L'illustration qu'il en donne ne détruit nullement l'impression d'archaïsme laissée par Robert.

Le Petit Larousse donne comme sens: "Partie de la chaussure qui est fixée à la semelle et qui entoure le pied », tandis que le Dictionnaire du français contemporain, miroir de la langue actuelle, offre deux définitions étrangères à l'acception que nous considérons ici: «1. Coup appliqué avec le plat de la main ... (sign.: gifle). 2. Groupe des spectateurs ... chargés d'applaudir bruyamment une pièce ».

Même si la définition donnée par le Larousse du $\mathrm{Xx}^{\mathrm{e}}$ siècle paraît assez bien convenir à cette pièce du costume que nous voulons désigner, il ne semble pas, $\mathrm{du}$ moins d'après les dictionnaires, que ce sens soit vivant ailleurs qu'au Canada.

Caoutchouc - Si l'on tient compte des illustrations données par le Larousse du $\mathrm{XX}^{\mathrm{e}}$ siècle au mot «caoutchouc», il ne fait pas de doute que ce qu'on y désigne du nom de caoutchouc correspond exactement à cet article du costume nommé aussi. «claque » au Canada.

Cependant ni le "grand》 Robert ni le Petit Larousse ne donnent ce sens précis au mot «caoutchouc». Mais voici que le Petit Robert termine en ces termes son article sur caoutchouc: «Plur. Chaussures de caoutchouc. «Elle me voyait chaussant mes caoutchoucs américains $\gg$ (Proust). V. snow-boot 》.

Or, nous traduisons ici snow-boots par couvre-chaussures, que Harrap seul mentionne, et qui désigne des bottillons ou des bottines de caoutchouc, tandis que la claque (ou le caoutchouc) évoque le soulier ou la claque d'une chaussure.

$\mathrm{Au}$ Canada, dans les années 40 , on a fait campagne pour imposer le mot 《caoutchouc» préférablement à «claque». Peut-être était-ce en invoquant l'autorité du Larousse du $\mathrm{xx}^{\mathrm{e}}$ siècle? Le mot «claque » est encore très vivant dans la langue populaire. "Caoutchouc»s'entend chez les gens-qui-soignent-leur-langage. 
REMORQUAGE À vos FRAIS (SAISIE)

Pour faire savoir aux automobilistes que leur voiture sera « saisie » et transportée dans un garage ou dans une fourrière s'ils ne tiennent pas compte des règlements de stationnement, on se sert au Canada de la formule précitée. Au mot « saisie », on lit au dictionnaire Larousse: «Action de s'emparer provisoirement des choses qui sont l'objet d'une contravention». Existe-t-il une autre formule en usage dans les pays francophones?

TRAMPOLIN, TRAMPOLINE OU TREMPOLIN

Ce doublet moderne de tremplin désigne « un tremplin très souple composé d'une toile assujettie dans un cadre au moyen de tendeurs élastiques $\gg$. Cet appareil sert en gymnastique.

Des dictionnaires consultés, seule l'Encyclopédie des sports de Larousse donne ce mot. Elle donne comme graphie «trampolin ou trampoline ». Si l'on ratifie cet emprunt, il nous semblerait préférable de le rapprocher de tremplin en l'orthographiant ainsi : «trempolin ». Nous souscrivons au principe qu'il faut franciser le plus possible les emprunts motivés pour en faciliter l'assimilation.

Comité de linguistique

RADIO-CANADA 